\title{
Trade and its trade-offs in the food system
}

\author{
An assessment of the climate vulnerability of the UK's fruit and vegetable supply is a useful starting point for \\ considering the health, environment, and social trade-offs of international trade in food.
}

\author{
Colin K. Khoury, Andy Jarvis and Andrew D. Jones
}

$\Lambda$ ligning multiple food system goals can uncover trade-offs and unexpected consequences ${ }^{1}$. In this issue of Nature Food, Scheelbeek and colleagues $^{2}$ reveal some of the complexities of moving towards healthier and more sustainable food systems, through a characterization of the UK's fruit and vegetable supply and its vulnerability to climate change.

Since the late 1980s the UK's food supply, including of fruits and vegetables, has become larger and more diverse per capita, with an increase in the availability of tropical fruits such as bananas and pineapples, and a decrease in the relative abundance of traditional vegetables such as cabbages, carrots, and peas ${ }^{2}$. This shift has been driven by economic development, demographic and cultural change, and globalization, and while increasing the local availability of internationally traded commodities, it also portends greater dietary homogeneity across food systems around the world ${ }^{3}$.

Increases in the diversity of the fruit and vegetable food supply may be indicative of enhanced food security at the national level - at least regarding availability. However, low intake of fruits and vegetables continues to be among the leading dietary risk factors for deaths and disability-adjusted life years globally and in many countries ${ }^{4}$, despite over 15 years of United Nations World Health Organization and Food and Agriculture Organization advocacy for increased production and consumption ${ }^{5}-$ and the UK is no exception. Only $30 \%$ of adults and $18 \%$ of children in England achieve the ' 5 a day' recommendation, with similar or lower levels in Scotland, Northern Ireland and Wales ${ }^{2}$. Furthermore, sugary fruits such as pineapples appear to be gaining favour in the UK food supply at the expense of leafy and leguminous vegetables ${ }^{2}$. Apples cannot be compared to oranges - much less to cabbages or peas.

Scheelbeek and colleagues traced the UK's fruit and vegetable supply chain over the last quarter century and found that the number of countries from which the UK imports and the total quantity of imported fruits and vegetables has increased, while domestic supply declined from $42 \%$ in the late 1980 s to $22 \%$ in 2013 . Using Notre Dame Global Adaptation Initiative (NDGAIN) country index scores supplemented by heat and water stress data, Scheelbeek and colleagues found that the supply of fruit and vegetables to the UK from climate-vulnerable countries such as Egypt and India increased from $20 \%$ to $32 \%$.

Given expected future production challenges due to temperature and precipitation extremes, as well as increasing occurrences of catastrophic weather events, greater reliance on fruit and vegetable imports from climate-vulnerable countries could negatively impact the availability of these healthy foods. Also, affordability, which already provides barriers to fruit and vegetable consumption ${ }^{6}$, would likely worsen, and without government intervention could disproportionately affect low-income families. Furthermore, climate change may also alter the perishability of fresh produce and therefore increase food loss and waste.

Additional research would be helpful to provide better resolution of vulnerabilities within cropping systems in source countries, but Scheelbeek and colleagues' results provide a useful starting point for considering health, environmental, and social trade-offs of trade in food. Trade has been perhaps the most effective response to food insufficiency over the past half-century globally, at least regarding calories ${ }^{7}$, and generates critical revenue for exporting countries $^{8}$. The UK is highly dependent on food imports, with affordable and available arable land being the major constraint to increasing local production ${ }^{9}$.

While there may be benefits to increasing local fruit and vegetable production, including lower transport emissions and new job opportunities, efforts by the UK to enhance the resilience and sustainability of its internationally sourced foods would be prudent. Approximately $76 \%$ of the water used in the UK fruit and vegetable supply chain is drawn elsewhere, including from water-scarce countries ${ }^{2}$, and water use efficiency in food trade itself has been worsening for decades ${ }^{10}$. Vast acreages of pasture in countries such as Australia and Brazil support UK meat demand ${ }^{8}$. Food system greenhouse gas emissions overwhelmingly occur during production, rather than in transport or other aspects of the supply chain ${ }^{11}$.

Including sustainability in trade criteria, as well as investing in the development and diffusion of technologies that enhance efficiencies and provide greater production and transport stability, would help nudge fruit and vegetable production systems around the world towards greater resilience. Ensuring that trade preferences align with international development objectives, and that the new technologies are widely available so as not to exacerbate economic opportunity disparities within the agricultural sectors of source countries, would also help to address equity challenges?.

Within the UK, making fruits and vegetables, and other healthy foods, the appealing, easy, and normal choice ${ }^{12}$, would improve human nutrition while mitigating land and water impacts, carbon emissions, and biodiversity loss, especially if they replace beef and other high-environmental-cost foods in the diet ${ }^{13}$. There is visible diversity and abundance of fruits and vegetables on offer in UK markets, and the resilience of their supply would perhaps have remained a distant concern for consumers had the COVID-19 pandemic not brought food vulnerability so markedly into the spotlight ${ }^{14}$. Such vulnerabilities may, in fact, be even more apparent with the withdrawal from the European Union ${ }^{15}$. The merger of the UK's Department for International Development with the Foreign and Commonwealth Office makes it all the more imperative that trade aligns with international development, delivering nutritional security and environmental sustainability not just for the UK but also the countries and communities it sources from. This time of unprecedented change is presenting opportunities to bring the wider 
and longer-term nutritional, environmental, and equity considerations of food systems to the table.

Colin K. Khoury (D) $1{ }^{凶}$, Andy Jarvis (D) 1,2 and Andrew D. Jones (D) 3

${ }^{1}$ International Center for Tropical Agriculture (CIAT), Cali, Colombia. ${ }^{2}$ CGIAR Research Program on Climate Change, Agriculture and Food Security (CCAFS), Cali, Colombia. ${ }^{3}$ School of Public Health, University of Michigan, Ann Arbor, MI, USA.

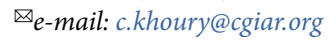

Published online: 9 November 2020 https://doi.org/10.1038/s43016-020-00169-6

References

1. Béné, C. et al. World Dev. 113, 116-130 (2019).

2. Scheelbeek, P. F. D. et al. Nat. Food https://doi.org/10.1038/ s43016-020-00179-4 (2020).

3. Khoury, C. K. et al. Proc. Natl Acad. Sci. USA 111, 4001-4006 (2014).

4. Afshin, A. et al. Lancet 393, 1958-1972 (2019).

5. Promoting Fruit and Vegetable Consumption Around the World (WHO, 2003); https://www.who.int/dietphysicalactivity/fruit/en/

6. Miller, V. et al. Lancet Glob. Health 4, e695-e703 (2016).

7. Porkka, M., Kummu, M., Siebert, S. \& Varis, O. PLoS ONE 8, e82714 (2013).
8. MacDonald, G. K. et al. BioScience 65, 275-289 (2015)

9. Fader, M., Gerten, D., Krause, M., Lucht, W. \& Cramer, W. Environ. Res. Lett. 8, 014046 (2013).

10. D’Odorico, P., Carr, J. A., Laio, F., Ridolfi, L. \& Vandoni, S. Earth's Future 2, 458-469 (2014).

11. Weber, C. L. \& Matthews, H. S. Environ. Sci. Technol. 42, 3508-3513 (2008)

12. Vermeulen, S. J., Park, T., Khoury, C. K. \& Béné, C. Ann. N. Y Acad. Sci. https://doi.org/10.1111/nyas.14446 (2020). 13. Stehfest, E. et al. Clim. Change 95, 83-102 (2009). 14. Garnett, P., Doherty, B. \& Heron, T. Nat. Food 1, 315-318 (2020). 15. Barons, M. J. \& Aspinall, W. BMJ Open 10, e032376 (2020).

Competing interests

The authors declare no competing interests. 